\title{
A Proposal for Practical Diagnosis of Renal Hypouricemia: Evidenced from Genetic Studies of Nonfunctional Variants of URAT1/SLC22A12 among 30,685 Japanese Individuals
}

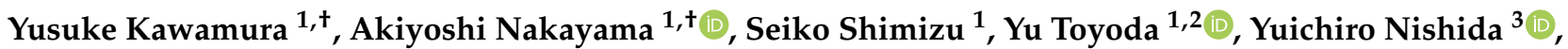 \\ Asahi Hishida ${ }^{4}$, Sakurako Katsuura-Kamano ${ }^{5}{ }^{\circledR}$, Kenichi Shibuya ${ }^{6,7}$, Takashi Tamura ${ }^{4}$, Makoto Kawaguchi ${ }^{1}$, \\ Satoko Suzuki ${ }^{8}$, Satoko Iwasawa ${ }^{8}$, Hiroshi Nakashima ${ }^{8}$, Rie Ibusuki ${ }^{6}$, Hirokazu Uemura ${ }^{9}$, Megumi Hara ${ }^{3}$, \\ Kenji Takeuchi ${ }^{4}{ }^{\mathbb{D}}$, Tappei Takada ${ }^{2}{ }^{\mathbb{D}}$, Masashi Tsunoda ${ }^{8}$, Kokichi Arisawa ${ }^{5}$, Toshiro Takezaki ${ }^{6}{ }^{\mathbb{D}}$, \\ Keitaro Tanaka ${ }^{3}$, Kimiyoshi Ichida ${ }^{10,11}$, Kenji Wakai ${ }^{4}$, Nariyoshi Shinomiya ${ }^{1} \mathbb{D}$ and Hirotaka Matsuo ${ }^{1, *}$
}

1 Department of Integrative Physiology and Bio-Nano Medicine, National Defense Medical College, Tokorozawa 359-8513, Japan; ykawamura@ndmc.ac.jp (Y.K.); aknak@ndmc.ac.jp (A.N.); s.shimizu11@gmail.com (S.S.); ytoyoda-tky@umin.ac.jp (Y.T.); makoto.kawaguchi.2920@gmail.com (M.K.); shinomi@ndmc.ac.jp (N.S.)

2 Department of Pharmacy, Faculty of Medicine, The University of Tokyo Hospital, The University of Tokyo, Tokyo 113-8655, Japan; tappei-tky@umin.ac.jp

check for updates

Citation: Kawamura, Y.; Nakayama, A.; Shimizu, S.; Toyoda, Y.; Nishida, Y.; Hishida, A.; Katsuura-Kamano, S.; Shibuya, K.; Tamura, T.; Kawaguchi, M.; et al. A Proposal for Practical Diagnosis of Renal Hypouricemia: Evidenced from Genetic Studies of Nonfunctional Variants of URAT1/SLC22A12 among 30,685 Japanese Individuals. Biomedicines 2021, 9, 1012. https://doi.org/ 10.3390/biomedicines 9081012

Academic Editor: Istvan Kovanecz

Received: 31 May 2021

Accepted: 9 August 2021

Published: 13 August 2021

Publisher's Note: MDPI stays neutral with regard to jurisdictional claims in published maps and institutional affiliations.

Copyright: (c) 2021 by the authors. Licensee MDPI, Basel, Switzerland. This article is an open access article distributed under the terms and conditions of the Creative Commons Attribution (CC BY) license (https:// creativecommons.org/licenses/by/ $4.0 /)$
3 Department of Preventive Medicine, Faculty of Medicine, Saga University, Saga 849-8501, Japan; ynishida@cc.saga-u.ac.jp (Y.N.); harameg@cc.saga-u.ac.jp (M.H.); tanakake@cc.saga-u.ac.jp (K.T.)

4 Department of Preventive Medicine, Graduate School of Medicine, Nagoya University, Nagoya 466-8550, Japan; a-hishi@med.nagoya-u.ac.jp (A.H.); ttamura@med.nagoya-u.ac.jp (T.T.); k.takeuchi@med.nagoya-u.ac.jp (K.T.); wakai@med.nagoya-u.ac.jp (K.W.)

5 Department of Preventive Medicine, Graduate School of Biomedical Sciences, Tokushima University, Tokushima 770-8503, Japan; skamano@tokushima-u.ac.jp (S.K.-K.); karisawa@tokushima-u.ac.jp (K.A.)

6 Department of International Island and Community Medicine, Graduate School of Medical and Dental Sciences, Kagoshima University, Kagoshima 890-8544, Japan; shibuya.kenichi@gmail.com (K.S.); iburie@m2.kufm.kagoshima-u.ac.jp (R.I.); takezaki@m.kufm.kagoshima-u.ac.jp (T.T.)

7 Department of Emergency and Intensive Care Medicine, Graduate School of Medical and Dental Sciences, Kagoshima University, Kagoshima 890-8544, Japan

8 Department of Preventive Medicine and Public Health, National Defense Medical College, Tokorozawa 359-8513, Japan; s-suzuki@ndmc.ac.jp (S.S.); iwasawa@ndmc.ac.jp (S.I.); hnakashi@ndmc.ac.jp (H.N.); mtsunoda@ndmc.ac.jp (M.T.)

9 Department of Health and Welfare System, College of Nursing Art and Science, University of Hyogo, Akashi 673-8588, Japan; hirokazu_uemura@cnas.u-hyogo.ac.jp

10 Department of Pathophysiology, Tokyo University of Pharmacy and Life Sciences, Tokyo 192-0392, Japan; ichida@toyaku.ac.jp

11 Division of Kidney and Hypertension, Department of Internal Medicine, Jikei University School of Medicine, Tokyo 105-8461, Japan

* Correspondence: hmatsuo.ndmc@gmail.com; Tel.: +81-4-2995-1482

+ The two authors equally contributed to this manuscript.

Abstract: Background: Renal hypouricemia (RHUC) is characterized by a low serum uric acid (SUA) level and high fractional excretion of uric acid $\left(\mathrm{FE}_{\mathrm{UA}}\right)$. Further studies on $\mathrm{FE}_{\mathrm{UA}}$ in hypouricemic individuals are needed for a more accurate diagnosis of RHUC. Methods: In 30,685 Japanese healthexamination participants, we genotyped the two most common nonfunctional variants of URAT1 (NFV-URAT1), W258X (rs121907892) and R90H (rs121907896), in 1040 hypouricemic individuals (SUA $\leq 3.0 \mathrm{mg} / \mathrm{dL}$ ) and 2240 individuals with FE $\mathrm{UA}_{\mathrm{UA}}$ data. The effects of NFV-URAT1 on FE $\mathrm{EA}_{\mathrm{UA}}$ and SUA were also investigated using linear and multiple regression analyses. Results: Frequency of hypouricemic individuals (SUA $\leq 3.0 \mathrm{mg} / \mathrm{dL}$ ) was $0.97 \%$ (male) and $6.94 \%$ (female) among 30,685 participants. High frequencies of those having at least one allele of NFV-URAT1 were observed in 1040 hypouricemic individuals. Furthermore, NFV-URAT1 significantly increased FE $\mathrm{UA}_{\mathrm{A}}$ and decreased SUA, enabling FE $\mathrm{EA}_{\mathrm{U}}$ and SUA levels to be estimated. Conversely, $\mathrm{FE}_{\mathrm{UA}}$ and SUA data of hypouricemic individuals are revealed to be useful to predict the number of NFV-URAT1. Conclusions: Our findings reveal that specific patterns of $\mathrm{FE}_{\mathrm{UA}}$ and SUA data assist with predicting 
the number of nonfunctional variants of causative genes for RHUC, and can also be useful for practical diagnosis of RHUC even before genetic tests.

Keywords: URAT1/SLC22A12; renal hypouricemia (RHUC); serum uric acid (SUA); fractional excretion of uric acid (FE $\left.\mathrm{UA}_{\mathrm{A}}\right)$

\section{Introduction}

Renal hypouricemia (RHUC), an overexcretion-type hypouricemia, is an inherited disorder caused by increased urinary urate excretion that results from insufficient renal urate reabsorption [1]. Dysfunctions in urate transporter 1 (URAT1) [2] and glucose transporter 9 (GLUT9) [3] respectively, cause RHUC type 1 and 2, showing low serum uric acid (SUA) levels and high fractional excretion of uric acid $\left(\mathrm{FE}_{\mathrm{UA}}\right)$. Although most hypouricemia patients are normally asymptomatic and are found by chance in health examinations, RHUC is sometimes accompanied by severe complications, such as exerciseinduced acute kidney injury (EIAKI) and urolithiasis [4,5].

Several urate transporters play an important physiological role in urate handling by urate excretion and reabsorption from the human kidney. SLC22A12/URAT1 is a causative gene for RHUC type 1 [2], and its nonfunctional variants of URAT1 (NFV-URAT1), W258X (rs121907892) and R90H (rs121907896), are reportedly the two most common causative variants in the Japanese population [6,7].

Several studies have previously reported the distribution of SUA levels in large Japanese populations [3,8-10]. Although the frequency of NFV-URAT1 is relatively high in Japanese people, the frequency of NFV-URAT1 in those with lower SUA $(\leq 3.0 \mathrm{mg} / \mathrm{dL})$ has not been studied in Japan or elsewhere. Furthermore, the effect size on $\mathrm{FE}_{\mathrm{UA}}$ of the number of alleles for NFV-URAT1 has never been clarified.

This state of affairs prompted us to investigate, in this study, the frequency of NFVURAT1 in 1040 hypouricemic individuals (SUA $\leq 3.0 \mathrm{mg} / \mathrm{dL}$ ) among 30,685 Japanese individuals undergoing health examinations. Using genetic analyses of these Japanese individuals, we evaluated the effect of NFV-URAT1 on FE $\mathrm{UA}_{\mathrm{A}}$ with the aim of being able to predict the presence and number of NFV-URAT1 from their FE $\mathrm{UA}_{\mathrm{A}}$ and SUA levels. This should lead to a more practical diagnosis of RHUC from patients' laboratory data.

\section{Materials and Methods}

\subsection{Study Participants}

This study was approved by the National Defense Medical College and Nagoya University's institutional ethical committees. We performed all the processes in accordance with the Declaration of Helsinki.

All the 30,685 Japanese participants (13,607 males and 17,078 females) in this study were recruited from participants in health examinations in the Shizuoka, Daiko (Aichi), Tokushima, Saga and Kagoshima areas in the Japan Multi-Institutional Collaborative Cohort Study (J-MICC Study) [11,12]. Written informed consent was obtained from each participant.

Those with low SUA of $\leq 3.0 \mathrm{mg} / \mathrm{dL}$ were defined as "hypouricemic individuals". Among them, those with SUA $\leq 2.0 \mathrm{mg} / \mathrm{dL}$ and $2.0 \mathrm{mg} / \mathrm{dL}<\mathrm{SUA} \leq 3.0 \mathrm{mg} / \mathrm{dL}$ were defined as "hypouricemia" and "mild hypouricemia", respectively. Hypouricemia was further divided into two groups: "severe hypouricemia" (SUA $\leq 1.0 \mathrm{mg} / \mathrm{dL}$ ) and "moderate hypouricemia" $(1.0<\mathrm{SUA} \leq 2.0 \mathrm{mg} / \mathrm{dL})$. When available, $\mathrm{FE}_{\mathrm{UA}}$ was calculated from the results of blood and urine tests using the equation: [urinary uric acid $(\mathrm{mg} / \mathrm{dL}) \times$ serum creatinine $(\mathrm{mg} / \mathrm{dL})] /[\mathrm{SUA}(\mathrm{mg} / \mathrm{dL}) \times$ urinary creatinine $(\mathrm{mg} / \mathrm{dL})][1,13]$. 


\subsection{Genetics Analysis}

The genomic DNA of each participant was extracted from whole peripheral blood cells. For genotyping, we performed the TaqMan method (Life Technologies, Carlsbad, CA, USA) using a LightCycler 480 (Roche Diagnostics, Mannheim, Germany), as described previously [7]. For NFV-URAT1, we genotyped the two most common variants (W258X and $\mathrm{R} 90 \mathrm{H})$. We used custom TaqMan assay probes designed for R90H, VIC-CCGCCACTTCCGC and FAM-CGCCGCTTCCGC, and for W258X, VIC-CGGGACTGAACACTG and FAMCGGGACTGGACACTG. Direct sequencing was performed with a 3130xl Genetic Analyzer (Life Technologies) to confirm all the heterozygotes and homozygotes of NFV-URAT1, using the following primers [7]: for R90H, forward $5^{\prime}$-GTTGGAGCCACCCCAAGTGAC- ${ }^{\prime}$ and reverse $5^{\prime}$-GTCTGACCCACCGTGATCCATG- $3^{\prime}$; for W258X, forward $5^{\prime}$-TGATGAACACG GGCACTCTC- $3^{\prime}$ and reverse $5^{\prime}$-CTTTCCACTCGCTCCCCTAG-3'.

\subsection{Data Analysis}

Linear regression analyses were performed to evaluate the influence of the allele of NFV-URAT1 on FE $\mathrm{UA}_{\mathrm{A}}$ or SUA. We also carried out multiple regression analysis in a stepwise method using the following equation: $y=\beta_{0}+\beta_{1} x_{1}+\beta_{2} x_{2}$, where $y$ is FE $\mathrm{UA}_{\mathrm{A}}$ or SUA levels, $\mathrm{x}_{1}$ is a dummy variable representing whether the number of alleles of NFV-URAT1 is one (one allele $=1$ and other $=0), x_{2}$ is a dummy variable representing whether the number of alleles of NFV-URAT1 is two (two alleles $=1$ and other $=0$ ) and $\beta_{0}, \beta_{1}$ and $\beta_{2}$ are partial regression coefficients for each covariate. We used SPSS v. 22 (IBM Japan, Tokyo, Japan) for all calculations in the statistical analyses carried out in this study.

\section{Results}

\subsection{Distribution of SUA Levels in the Japanese Population}

Table 1 shows the distribution of SUA levels of the 30,685 Japanese health examination participants (13,607 males and 17,078 females). Among the 30,685 participants, the prevalence of hypouricemia (SUA $\leq 2.0 \mathrm{mg} / \mathrm{dL}$ ) was $0.18 \%$ in males and $0.54 \%$ in females. Mild hypouricemia $(2.0<\mathrm{SUA} \leq 3.0 \mathrm{mg} / \mathrm{dL})$ was observed in 107 males $(0.79 \%)$ and 1093 females $(6.40 \%)$. Hypouricemic individuals (SUA $\leq 3.0 \mathrm{mg} / \mathrm{dL}$ ) consisted of 131 males $(0.97 \%)$ and 1186 females $(6.94 \%)$. The frequency of moderate hypouricemia in males $(1.0<$ SUA $\leq 2.0 \mathrm{mg} / \mathrm{dL})$ was $0.03 \%$, the fewest in all male participants according to the ranked classification of SUA used in this study (Table 1). Contrary to the pattern seen in hypouricemic individuals (SUA $\leq 3.0 \mathrm{mg} / \mathrm{dL}$ ), the frequency of hyperuricemia (SUA $>7.0 \mathrm{mg} / \mathrm{dL}$ ) was $20.28 \%$ for males and $1.11 \%$ for females.

Table 1. Distribution of SUA levels of 30,685 Japanese health examination participants.

\begin{tabular}{ccccc}
\hline \multirow{2}{*}{ SUA (mg/dL) } & \multicolumn{2}{c}{ Male } & \multicolumn{2}{c}{ Female } \\
\cline { 2 - 5 } & Number & Frequency (\%) & Number & Frequency (\%) \\
\hline $0.0-1.0$ & 20 & 0.15 & 23 & 0.13 \\
$1.1-2.0$ & 4 & 0.03 & 70 & 0.41 \\
$2.1-3.0$ & 107 & 0.79 & 1093 & 6.40 \\
$3.1-7.0$ & 10,716 & 78.75 & 15,703 & 91.95 \\
$7.1-8.0$ & 1956 & 14.37 & 149 & 0.87 \\
$8.1-9.0$ & 625 & 4.59 & 32 & 0.19 \\
$9.1-$ & 179 & 1.32 & 8 & 0.05 \\
\hline Total & 13,607 & 100 & 17,078 & 100 \\
\hline
\end{tabular}

30,685 subjects (13,607 males and 17,078 females) were recruited from health examination participants at 5 collection sites for the Japan Multi-Institutional Collaborative Cohort Study (J-MICC Study). Frequency of hypouricemia (SUA of $\leq 2.0 \mathrm{mg} / \mathrm{dL}$ ) was $0.18 \%$ (males) and $0.54 \%$ (females) among the 30,685 participants. Frequency of hypouricemic individuals (SUA of $\leq 3.0 \mathrm{mg} / \mathrm{dL}$ ) was $0.97 \%$ (males) and $6.94 \%$ (females) among the 30,685 participants. SUA, serum uric acid. 


\subsection{Frequency of NFV-URAT1 in Hypouricemic Individuals}

As displayed in Figure 1, 1040 hypouricemic individuals (SUA $\leq 3.0 \mathrm{mg} / \mathrm{dL}$ ) were selected from the whole population of participants to investigate the frequency of NFVURAT1. The characteristics of these hypouricemic individuals (SUA $\leq 3.0 \mathrm{mg} / \mathrm{dL}$ ) are shown in Table 2. Table 3 indicates the relationship between the number of NFV-URAT1 and hypouricemic populations. As shown here, those with two NFV-URAT1 alleles were seen only in severe hypouricemia in both sexes. For mild hypouricemia, the largest population was males with one NFV-URAT1 allele, although it was those with 0 alleles in females. Of the mild hypouricemia individuals, at least two thirds of the males and one third of the females were assumed to be the "mild" RHUC type 1 due to having only one NFV-URAT1 allele.

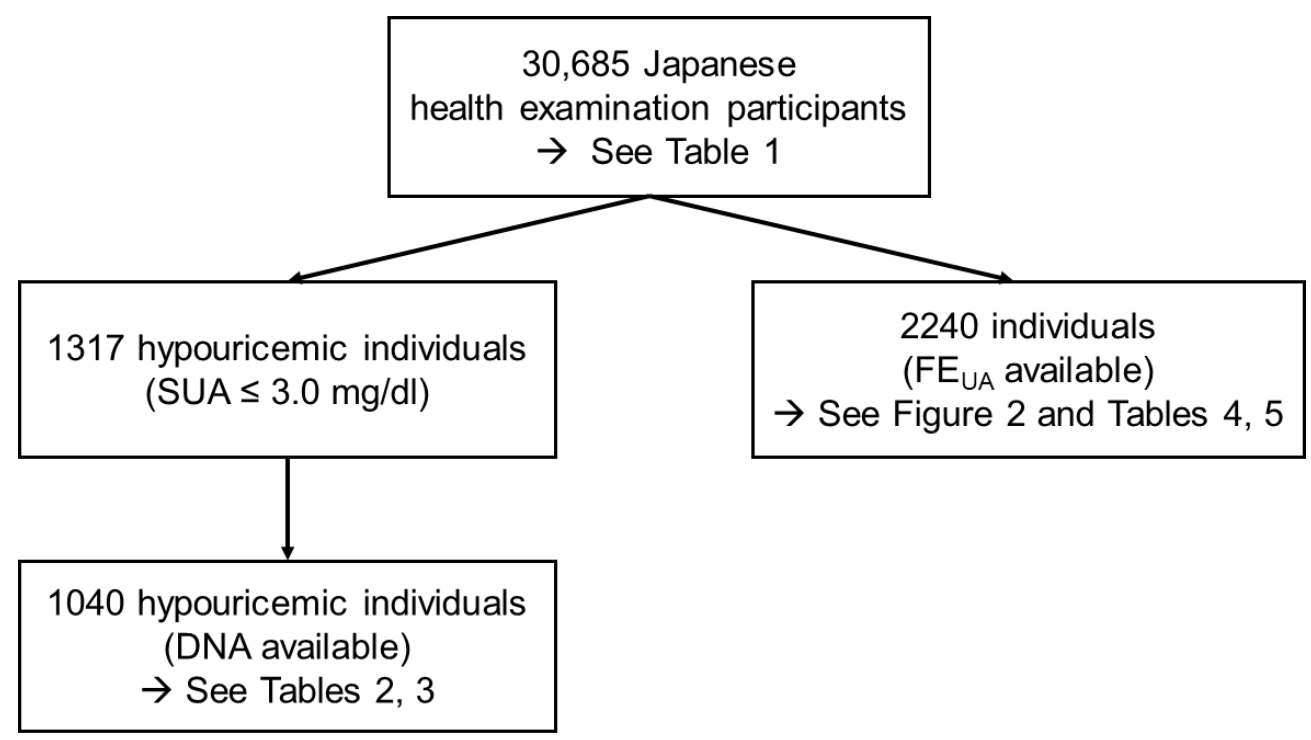

Figure 1. Selection of participants for each analysis. We first collected SUA data from 30,685 Japanese participants $(13,607$ males and 17,078 females) to gain an understanding of the distribution of SUA levels in the Japanese general population. Second, to investigate the frequency of NFV-URAT1 alleles, 1040 hypouricemic individuals (108 males and 932 females) with SUA of $\leq 3.0 \mathrm{mg} / \mathrm{dL}$ and whose genomic DNA samples were available were selected from 1317 hypouricemic individuals. Third, to evaluate the relationship between NFV-URAT1 and FE $\mathrm{UA}_{\mathrm{A}}$ or SUA, 2240 individuals (1542 males and 698 females) whose $\mathrm{FE}_{\mathrm{UA}}$ data were available were also selected from all 30,685 participants. SUA, serum uric acid; $F_{\mathrm{UA}}$, fractional excretion of uric acid; NFV-URAT1, nonfunctional variants of URAT1.

Table 2. Characteristics of 1040 hypouricemic individuals.

\begin{tabular}{|c|c|c|c|c|c|c|}
\hline & \multicolumn{3}{|c|}{ Male } & \multicolumn{3}{|c|}{ Female } \\
\hline & Number & Age (year) & BMI $\left(\mathrm{kg} / \mathrm{m}^{2}\right)$ & Number & Age (year) & BMI $\left(\mathrm{kg} / \mathrm{m}^{2}\right)$ \\
\hline Severe hypouricemia $(0.0-1.0 \mathrm{mg} / \mathrm{dL})$ & 17 & $56.4 \pm 8.1$ & $24.2 \pm 2.6$ & 19 & $55.7 \pm 8.1$ & $22.1 \pm 2.9$ \\
\hline Moderate hypouricemia (1.1-2.0 mg/dL) & 4 & $53.5 \pm 8.3$ & $24.1 \pm 2.1$ & 57 & $50.2 \pm 8.4$ & $21.3 \pm 3.1$ \\
\hline Mild hypouricemia $(2.1-3.0 \mathrm{mg} / \mathrm{dL})$ & 87 & $56.0 \pm 8.9$ & $22.6 \pm 2.9$ & 856 & $51.8 \pm 9.2$ & $21.1 \pm 2.9$ \\
\hline Hypouricemia $(\leq 2.0 \mathrm{mg} / \mathrm{dL})$ & 21 & $55.8 \pm 8.2$ & $24.2 \pm 2.5$ & 76 & $51.6 \pm 8.7$ & $21.5 \pm 3.1$ \\
\hline $\begin{array}{l}\text { Hypouricemia + mild hypouricemia } \\
\qquad(\leq 3.0 \mathrm{mg} / \mathrm{dL})\end{array}$ & 108 & $56.0 \pm 8.7$ & $22.9 \pm 2.9$ & 932 & $51.8 \pm 9.1$ & $21.2 \pm 2.9$ \\
\hline
\end{tabular}

See Figure 1 for the selection of 1040 hypouricemic individuals (SUA $\leq 3.0 \mathrm{mg} / \mathrm{dL}$ ) from 30,685 Japanese health examination participants. Plus/minus values are means \pm SD. BMI, body mass index; SUA, serum uric acid. 
Table 3. The frequency of NFV-URAT1 in 1040 hypouricemic individuals.

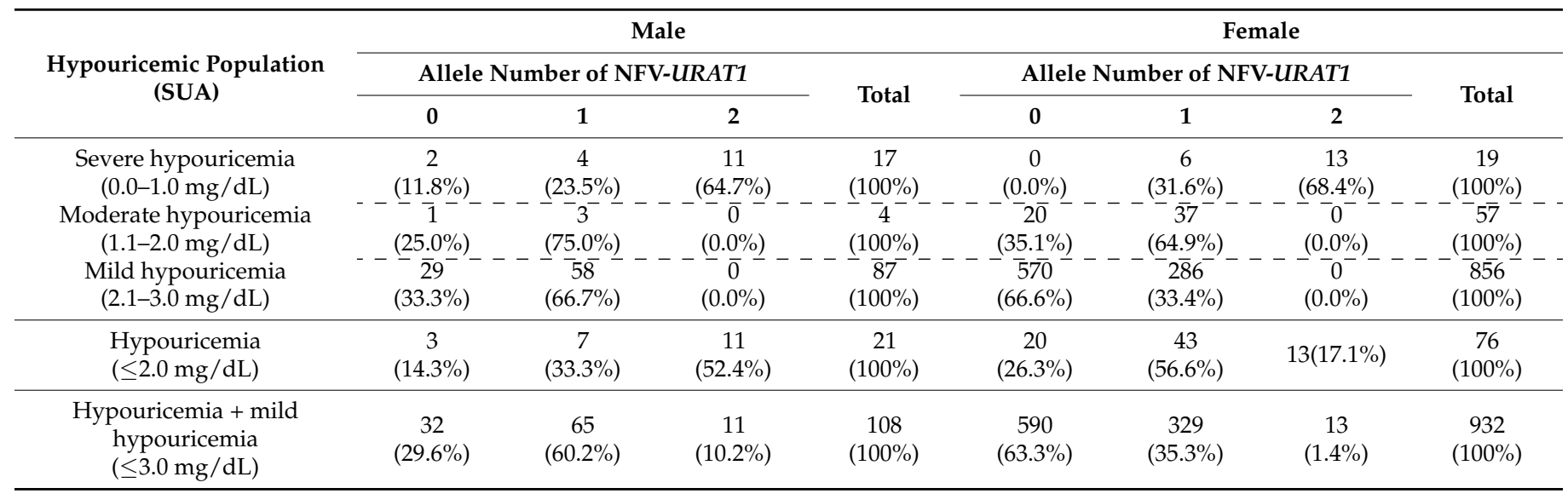

See Figure 1 for the selection of 1040 hypouricemic individuals (SUA $\leq 3.0 \mathrm{mg} / \mathrm{dL}$ ) from 30,685 Japanese health examination participants. W258X and $\mathrm{R} 90 \mathrm{H}$, the two most common variants of URAT1, were selected as NFV-URAT1 in this study. NFV-URAT1, nonfunctional variants of URAT1; SUA, serum uric acid.

\subsection{Associations between NFV-URAT1 and FE $U A$ or SUA in 2240 Japanese Individuals}

We evaluated the relationship between NFV-URAT1 and FE $\mathrm{UA}_{\mathrm{A}}$ or SUA in 2240 Japanese individuals (Figure 1) whose $\mathrm{FE}_{\mathrm{UA}}$ data were available. Figure 2 shows that, in both sexes, NFV-URAT1 alleles significantly increased $\mathrm{FE}_{\mathrm{UA}}\left(p=1.27 \times 10^{-46}\right.$ in males and $5.09 \times 10^{-27}$ in females $)$ and decreased SUA $\left(p=2.47 \times 10^{-53}\right.$ in males and $2.14 \times 10^{-13}$ in females). The mean FE $\mathrm{UA}_{\mathrm{U}}$ levels of those with 0,1 and 2 alleles for NFV-URAT1 were $3.94 \% \pm 0.06 \%, 6.57 \% \pm 0.39 \%$ and $42.6 \% \pm 12.8 \%$ in males, and $5.37 \% \pm 0.10 \%$, $6.43 \% \pm 0.67 \%$ and $45.9 \% \pm 3.81 \%$ in females, respectively (Figure $2 \mathrm{a}$ ). The mean SUA levels of those with 0,1 and 2 alleles of NFV-URAT1 were $6.10 \pm 0.03$ (mg/dL), $4.17 \pm 0.11(\mathrm{mg} / \mathrm{dL})$ and $0.75 \pm 0.04(\mathrm{mg} / \mathrm{dL})$ in males, and in females were $4.56 \pm 0.04(\mathrm{mg} / \mathrm{dL}), 3.31 \pm 0.19(\mathrm{mg} / \mathrm{dL})$ and $0.65 \pm 0.11(\mathrm{mg} / \mathrm{dL})$, respectively (Figure $2 \mathrm{~b})$.

(a)

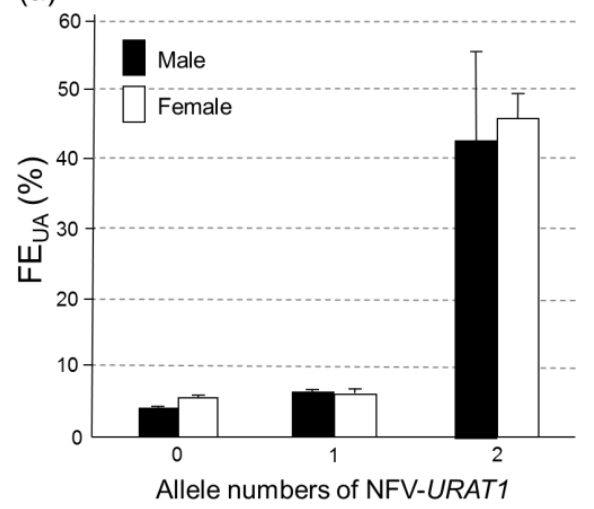

(b)

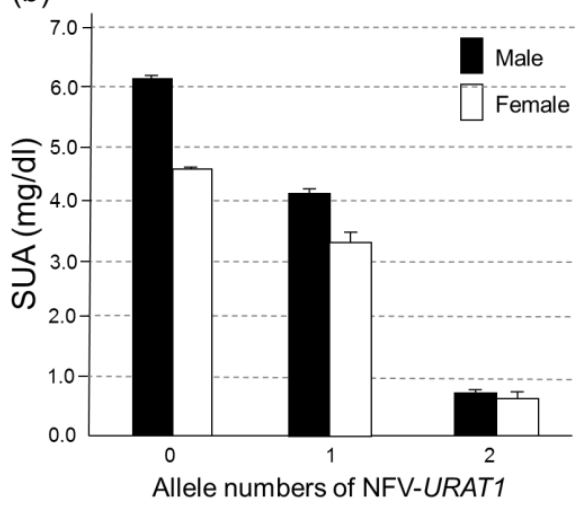

Figure 2. The effect on $\mathrm{FE}_{\mathrm{UA}}$ and SUA levels of NFV-URAT1 in 2240 Japanese participants: (a) FE and (b) SUA levels of participants with 0, 1 and 2 alleles of NFV-URAT1 are shown for each sex. Among the 1542 male participants (black bars), 1472, 68 and 2 participants had 0, 1 and 2 alleles of NFV-URAT1, respectively. Among the 698 female participants (white bars), 678, 18 and 2 participants had 0,1 and 2 alleles of NFV-URAT1, respectively. The presence of NFV-URAT1 alleles significantly increased $\mathrm{FE}_{\mathrm{UA}}\left(p=1.27 \times 10^{-46}\right.$ in males and $p=5.09 \times 10^{-27}$ in females), and significantly decreased SUA $\left(p=2.47 \times 10^{-53}\right.$ in males and $p=2.14 \times 10^{-13}$ in females $)$. W258X and $\mathrm{R} 90 \mathrm{H}$, the two most common variants of URAT1, were selected as NFV-URAT1 in this study. All bars are expressed as means \pm SE. FEUA, fractional excretion of uric acid; SUA, serum uric acid; NFV-URAT1, nonfunctional variants of URAT1. 
Table 4 shows laboratory data including $\mathrm{FE}_{\mathrm{UA}}$, SUA levels and NFV-URAT1 of 52 hypouricemia and mild hypouricemia individuals (SUA $\leq 3.0 \mathrm{mg} / \mathrm{dL}$ ) among those 2240 individuals whose $\mathrm{FE}_{\mathrm{UA}}$ data were available (Figure 1). All four individuals (two males and two females) with two NFV-URAT1 alleles showed high $\mathrm{FE}_{\mathrm{UA}}$ (mean: $44.3 \%$; range: $24.5-60.7 \%$ ) and extremely low SUA levels of $\leq 1.0 \mathrm{mg} / \mathrm{dL}$ (severe hypouricemia). On the other hand, the other 48 individuals ( 6 males and 42 females) with one or no NFV-URAT1 alleles displayed a mean $\mathrm{FE}_{\mathrm{UA}}$ level of $8.01 \%$ (range: $2.05-16.86 \%$ ). Most of them were mild hypouricemia (Table 4).

Table 4. Laboratory data and NFV-URAT1 of 52 hypouricemic individuals.

\begin{tabular}{|c|c|c|c|c|c|c|c|}
\hline \multirow[b]{2}{*}{ Case No. } & \multirow[b]{2}{*}{ Sex } & \multirow[b]{2}{*}{ Age } & \multicolumn{2}{|c|}{ NFV-URAT1 } & \multirow[b]{2}{*}{$\mathrm{FE}_{\mathrm{UA}}(\%)$} & \multirow[b]{2}{*}{ SUA (mg/dL) } & \multirow[b]{2}{*}{$\mathrm{SCr}(\mathrm{mg} / \mathrm{dL})$} \\
\hline & & & $\begin{array}{c}\text { Number of } \\
\text { Alleles }\end{array}$ & $\begin{array}{l}\text { Amino Acid } \\
\text { Substitution }\end{array}$ & & & \\
\hline 1 & Female & 69 & 2 & W258X/W258X & 51.32 & 0.5 & 0.6 \\
\hline 2 & Male & 63 & 2 & W258X/W258X & 60.71 & 0.7 & 0.8 \\
\hline 3 & Female & 68 & 2 & W258X/W258X & 40.55 & 0.8 & 0.7 \\
\hline 4 & Male & 57 & 2 & W258X/W258X & 24.52 & 0.8 & 1.0 \\
\hline$\overline{5}^{-}$ & Female & $\overline{4} 5^{-}$ & $1^{-}$ & ${ }^{-} \overline{\mathrm{W}} \overline{2} 5 \overline{8} \overline{\mathrm{X}} \mathrm{J}^{---}$ & $\overline{12.0} 8^{-}$ & $--\overline{2.3}$ & $0.6^{-}$ \\
\hline 6 & Female & 56 & 1 & W258X/ & 5.67 & 2.4 & 0.8 \\
\hline 7 & Male & 69 & 1 & W258X/ & 7.80 & 2.4 & 0.7 \\
\hline 8 & Female & 61 & 1 & W258X/ & 6.04 & 2.5 & 0.5 \\
\hline 9 & Female & 51 & 1 & W258X/ & 6.40 & 2.6 & 0.6 \\
\hline 10 & Female & 70 & 1 & W258X/ & 6.97 & 2.6 & 0.6 \\
\hline 11 & Female & 68 & 1 & W258X/ & 2.17 & 2.8 & 0.6 \\
\hline 12 & Female & 55 & 1 & W258X/ & 10.41 & 2.9 & 0.7 \\
\hline 13 & Female & 41 & 1 & W258X/ & 11.12 & 2.9 & 0.4 \\
\hline 14 & Male & 69 & 1 & W258X/ & 12.51 & 3.0 & 0.9 \\
\hline 15 & Male & 55 & 1 & W258X/ & 8.19 & 3.0 & 0.9 \\
\hline 16 & Female & 46 & 1 & R90H/ & 6.55 & 3.0 & 0.5 \\
\hline$\overline{17}^{-}$ & Female & 65 & $0^{-}$ & & $\overline{12 . \overline{4} 5}$ & 2.0 & $0.5^{-}$ \\
\hline 18 & Male & 54 & 0 & & 4.07 & 2.3 & 0.6 \\
\hline 19 & Female & 61 & 0 & & 14.75 & 2.3 & 0.5 \\
\hline 20 & Female & 62 & 0 & & 3.40 & 2.5 & 0.5 \\
\hline 21 & Female & 45 & 0 & & 3.10 & 2.6 & 0.6 \\
\hline 22 & Female & 71 & 0 & & 12.32 & 2.6 & 0.6 \\
\hline 23 & Male & 52 & 0 & & 4.91 & 2.6 & 0.7 \\
\hline 24 & Female & 50 & 0 & & 2.94 & 2.7 & 0.6 \\
\hline 25 & Female & 54 & 0 & & 6.16 & 2.7 & 0.6 \\
\hline 26 & Female & 52 & 0 & & 2.05 & 2.7 & 0.6 \\
\hline 27 & Female & 62 & 0 & & 9.51 & 2.8 & 0.5 \\
\hline 28 & Female & 41 & 0 & & 7.86 & 2.8 & 0.6 \\
\hline 29 & Female & 62 & 0 & & 11.76 & 2.8 & 0.5 \\
\hline 30 & Female & 58 & 0 & & 12.11 & 2.8 & 0.6 \\
\hline 31 & Female & 47 & 0 & & 6.77 & 2.8 & 0.7 \\
\hline 32 & Female & 43 & 0 & & 8.11 & 2.8 & 0.5 \\
\hline 33 & Female & 41 & 0 & & 8.17 & 2.8 & 0.6 \\
\hline 34 & Female & 60 & 0 & & 5.88 & 2.8 & 0.7 \\
\hline 35 & Male & 59 & 0 & & 16.86 & 2.8 & 0.8 \\
\hline 36 & Female & 51 & 0 & & 5.27 & 2.8 & 0.7 \\
\hline 37 & Female & 58 & 0 & & 12.61 & 2.9 & 0.5 \\
\hline 38 & Female & 43 & 0 & & 6.64 & 2.9 & 0.7 \\
\hline 39 & Female & 47 & 0 & & 7.90 & 2.9 & 0.6 \\
\hline 40 & Female & 68 & 0 & & 8.14 & 2.9 & 0.7 \\
\hline 41 & Female & 72 & 0 & & 14.10 & 2.9 & 0.4 \\
\hline 42 & Female & 52 & 0 & & 5.91 & 3.0 & 0.6 \\
\hline 43 & Female & 63 & 0 & & 6.07 & 3.0 & 0.5 \\
\hline 44 & Female & 51 & 0 & & 8.29 & 3.0 & 0.5 \\
\hline 45 & Female & 69 & 0 & & 8.17 & 3.0 & 0.5 \\
\hline 46 & Female & 47 & 0 & & 8.15 & 3.0 & 0.6 \\
\hline 47 & Female & 74 & 0 & & 3.34 & 3.0 & 0.6 \\
\hline 48 & Female & 59 & 0 & & 10.43 & 3.0 & 0.6 \\
\hline
\end{tabular}


Table 4. Cont.

\begin{tabular}{|c|c|c|c|c|c|c|c|}
\hline \multirow[b]{2}{*}{ Case No. } & \multirow[b]{2}{*}{ Sex } & \multirow[b]{2}{*}{ Age } & \multicolumn{2}{|c|}{ NFV-URAT1 } & \multirow[b]{2}{*}{$\mathrm{FE}_{\mathrm{UA}}(\%)$} & \multirow[b]{2}{*}{ SUA (mg/dL) } & \multirow[b]{2}{*}{$\mathrm{SCr}(\mathrm{mg} / \mathrm{dL})$} \\
\hline & & & $\begin{array}{l}\text { Number of } \\
\text { Alleles }\end{array}$ & $\begin{array}{l}\text { Amino Acid } \\
\text { Substitution }\end{array}$ & & & \\
\hline 49 & Female & 50 & 0 & & 8.68 & 3.0 & 0.6 \\
\hline 50 & Female & 60 & 0 & & 9.96 & 3.0 & 0.6 \\
\hline 51 & Female & 56 & 0 & & 7.68 & 3.0 & 0.6 \\
\hline 52 & Female & 64 & 0 & & 4.17 & 3.0 & 0.6 \\
\hline
\end{tabular}

Fifty-two hypouricemic individuals (SUA $\leq 3.0 \mathrm{mg} / \mathrm{dL}$ ) were found among 2240 individuals whose FEUA data were available. These 52 hypouricemic individuals include 4 hypouricemia cases (SUA $\leq 2.0 \mathrm{mg} / \mathrm{dL} ; 2$ males and 2 females) with 2 alleles of NFV-URAT1, and 47 mild hypouricemia cases $(2.0<\mathrm{SUA} \leq 3.0 \mathrm{mg} / \mathrm{dL} ; 6$ males and 41 females $)$ with 1 or 0 alleles of NFV-URAT1. Four hypouricemia cases with two alleles of NFV-URAT1 (Case Nos. 1-4) exhibit severe hypouricemia (SUA $\leq 1.0 \mathrm{mg} / \mathrm{dL}$ ), and the average of their $\mathrm{FE}_{\mathrm{UA}}$ was $44.3 \%$ (range: $24.5-60.7 \%$ ). On the other hand, the average of FE $\mathrm{UA}_{\mathrm{A}}$ for 12 mild hypouricemia with only 1 allele of NFV-URAT1 (Case Nos. 5-16) was $7.99 \%$ (range: $2.17-12.51 \%$ ). Case No. 17 (hypouricemia) exhibits an SUA of $2.0 \mathrm{mg} / \mathrm{dL}$ and $\mathrm{FE}_{\mathrm{UA}}$ of $12.45 \%$, suggesting this individual to also be a renal hypouricemia (RHUC) case with a different (but only one) nonfunctional variant of URAT1/SLC22A12 (or GLUT9/SLC2A9). Case Nos. 18-52 had mild hypouricemia, showing an SUA of $2.1-3.0 \mathrm{mg} / \mathrm{dL}$ and FE $\mathrm{UA}_{\mathrm{A}}$ of $2.05-16.86 \%$, values very similar to those of cases Nos. 5-16 who have one NFV-URAT1 allele. Therefore, case Nos. 18-52 appear to have a different (but only one) nonfunctional variant of URAT1/SLC22A12 (or GLUT9/SLC2A9). W258X and R90H, the two most common variants of URAT1, were selected as NFV-URAT1 in this study. NFV-URAT1, nonfunctional variants of URAT1; $\mathrm{FE}_{\mathrm{UA}}$, fractional excretion of uric acid; SUA, serum uric acid; SCr, serum creatinine.

\subsection{The Effect on FE $E_{U A}$ and SUA Levels of the Number of Alleles of NFV-URAT1}

Table 5 shows the results of multiple regression analyses on $\mathrm{FE}_{\mathrm{UA}}$ and SUA levels by the number of alleles of NFV-URAT1. Two alleles of NFV-URAT1 $\left(\beta_{2}\right)$ markedly elevated $\mathrm{FE}_{\mathrm{UA}}$ in both sexes by approximately $40 \%\left(\beta=38.68, p=1.35 \times 10^{-108}\right.$ for males, $\beta=40.54$, $p=2.15 \times 10^{-79}$ for females). One allele of NFV-URAT1 $\left(\beta_{1}\right)$ gave significantly elevated $\mathrm{FE}_{\mathrm{UA}}$ in males $\left(\beta=2.63, p=4.04 \times 10^{-20}\right)$, but the variance of one allele of NFV-URAT1 was eliminated for females in this multiple regression analysis. Conversely, two alleles of NFVURAT1 $\left(\beta_{2}\right)$ markedly reduced SUA levels $\left(\beta=-5.35, p=2.39 \times 10^{-12}\right.$ for male, $\beta=-3.91$, $p=2.97 \times 10^{-8}$ for females). One allele of NFV-URAT1 $\left(\beta_{1}\right)$ also significantly reduced SUA levels ( $\beta=-1.93, p=6.56 \times 10^{-45}$ for males, $\beta=-1.25, p=1.53 \times 10^{-7}$ for females). In other words, these results indicate that $\mathrm{FE}_{\mathrm{UA}}$ and SUA levels can be estimated from the genotyping results of NFV-URAT1 (W258X and R90H), and, vice versa, from the clinical data (FE $\mathrm{UA}_{\mathrm{A}}$ and SUA levels), we can predict the presence and number of NFV-URAT1, which can reveal whether or not a patient is RHUC type 1.

Table 5. Multiple regression analysis of $\mathrm{FE}_{\mathrm{UA}}$ and SUA along the number of NFV-URAT1.

\begin{tabular}{|c|c|c|c|c|c|}
\hline & & \multicolumn{2}{|l|}{ Male } & \multicolumn{2}{|l|}{ Female } \\
\hline & & Partial Regression Coefficient & $p$ Value & Partial Regression Coefficient & $p$ Value \\
\hline \multirow{3}{*}{$\mathrm{FE}_{\mathrm{UA}}$} & $\beta_{0}$ & 3.94 & 0 & 5.40 & $1.61 \times 10^{-249}$ \\
\hline & $\beta_{1}$ & 2.63 & $4.04 \times 10^{-20}$ & - & - \\
\hline & $\beta_{2}$ & 38.68 & $1.35 \times 10^{-108}$ & 40.54 & $2.15 \times 10^{-79}$ \\
\hline \multirow{3}{*}{ SUA } & $\beta_{0}$ & 6.10 & 0 & 4.56 & 0 \\
\hline & $\beta_{1}$ & -1.93 & $6.56 \times 10^{-45}$ & -1.25 & $1.53 \times 10^{-7}$ \\
\hline & $\beta_{2}$ & -5.35 & $2.39 \times 10^{-12}$ & -3.91 & $2.97 \times 10^{-8}$ \\
\hline
\end{tabular}

2240 individuals (1542 males and 698 females) with their $\mathrm{FE}_{\mathrm{UA}}$ data available were analyzed. $\mathrm{y}=\beta_{0}+\beta_{1} \mathrm{x}_{1}+\beta_{2} \mathrm{x}_{2}$, where $\mathrm{y}$ is FE $\mathrm{FA}$ or SUA levels, $x_{1}$ is a dummy variable representing whether the number of alleles on NFV-URAT1 is one (one allele $=1$ and other $=0$ ) and $x_{2}$ is a dummy variable representing whether the number of alleles on NFV-URAT1 is two (two alleles $=1$ and other $=0$ ). W258X and R90H, the two most common variants of URAT1, were selected as NFV-URAT1 in this study. -, eliminated from covariance. $\mathrm{FE}_{\mathrm{UA}}$, fractional excretion of uric acid; SUA, serum uric acid; NFV-URAT1, nonfunctional variants of URAT1.

\section{Discussion}

In this study, we demonstrated the prevalence of hypouricemia (SUA $\leq 2.0 \mathrm{mg} / \mathrm{dL}$ ) and mild hypouricemia $(2.0<\mathrm{SUA} \leq 3.0 \mathrm{mg} / \mathrm{dL})$ in a general Japanese population (Table 1$)$, the frequency of NFV-URAT1 in hypouricemic individuals (Table 3) and the effect of NFV-

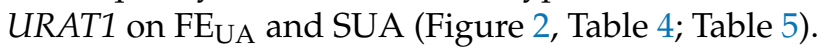

The prevalence of hypouricemia (SUA $\leq 2.0 \mathrm{mg} / \mathrm{dL}$ ) was $0.18 \%$ for males and $0.54 \%$ for females in the present study (Table 1), which is consistent with previous reports 
and the clinical practice guideline for RHUC $[1,8,10]$. The prevalence of hypouricemia $(\mathrm{SUA} \leq 2.0 \mathrm{mg} / \mathrm{dL}$ ) in the previous report [1] was approximately $0.2 \%$ for males and $0.4 \%$ for females in the general Japanese population. The prevalence of mild hypouricemia $(2.0<\mathrm{SUA} \leq 3.0 \mathrm{mg} / \mathrm{dL})$ and hypouricemic individuals (SUA $\leq 3.0 \mathrm{mg} / \mathrm{dL})$ was also reported in the present study. The prevalence of moderate hypouricemia $(1.0<\mathrm{SUA} \leq 2.0 \mathrm{mg} / \mathrm{dL})$ was $0.03 \%$ for males, the lowest among all the participants (Table 1 ), also consistent with previous reports $[3,10]$.

Although the frequency of NFV-URAT1 is high in Japanese [1] and European Roma populations [14,15], this is the first report on the frequencies of those having 0,1 and 2 alleles of NFV-URAT1 (W258X and R90H) in the general population of hypouricemia and mild hypouricemia individuals (SUA $\leq 3.0 \mathrm{mg} / \mathrm{dL}$ ).

High frequencies of NFV-URAT1 (in total $85.7 \%$ and $73.7 \%$ in males and females) are observed among hypouricemia (SUA $\leq 2.0 \mathrm{mg} / \mathrm{dL}$; Table 3), suggesting that more than $70 \%$ of hypouricemic individuals (SUA $\leq 2.0 \mathrm{mg} / \mathrm{dL}$ ) appear to have RHUC type 1 due to one or two NFV-URAT1 alleles. Table 3 also indicates that even in mild hypouricemia $(2.0<\mathrm{SUA} \leq 3.0 \mathrm{mg} / \mathrm{dL})$, at least two thirds of men and one third of women are estimated to be the "mild" RHUC type 1 due to the presence of only one NFV-URAT1. These results indicate that RHUC or "mild" RHUC should be suspected when examining hypouricemic individuals (SUA $\leq 3.0 \mathrm{mg} / \mathrm{dL}$ ), as the clinical practice guideline for RHUC recommends in its clinical algorithm $[1,16]$. This study, however, was performed focusing solely on the two most common NFV-URAT1 alleles (W258X and R90H). Further studies to identify other known dysfunctional variants $[2,6,17-20]$ are needed, as well as the genotyping of novel variants of URAT1 to be able to more accurately elucidate the frequency of RHUC type 1 in hypouricemic individuals (SUA $\leq 3.0 \mathrm{mg} / \mathrm{dL}$ ).

We have for the first time demonstrated that NFV-URAT1 significantly increases $\mathrm{FE}_{\mathrm{UA}}$ and decreases SUA, using 2240 individuals whose $\mathrm{FE}_{\mathrm{UA}}$ data were available (Figure 2). Furthermore, as shown in Table 5, we have proven that FE $\mathrm{EA}_{\mathrm{UA}}$ and SUA levels can be estimated from the number of alleles of NFV-URAT1 (W258X and R90H). We also suggest that it is possible to predict the presence and number of NFV-URAT1 alleles from laboratory data ( $\mathrm{FE}_{\mathrm{UA}}$ and SUA levels). Of 52 hypouricemic individuals, 4 individuals (Cases Nos. 1-4 in Table 4), with 2 NFV-URAT1 alleles, exhibited severe hypouricemia and high $\mathrm{FE}_{\mathrm{UA}}$. On the other hand, most of the other 48 hypouricemic individuals (Case Nos. 5-52 in Table 4), with 1 or 0 NFV-URAT1 alleles, exhibited mild hypouricemia and showed normal or slightly high $\mathrm{FE}_{\mathrm{UA}}$. In other words, the high $\mathrm{FE}_{\mathrm{UA}}$ that is seen in severe hypouricemia is a useful predictor of the presence of two NFV-URAT1 alleles, and the normal or slightly high $\mathrm{FE}_{\mathrm{UA}}$ seen in mild hypouricemia also helps to predict the presence of one or zero NFV-URAT1 alleles.

The limitations of the present study are as follows: (1) menopausal status was not considered, and (2) the influence of environmental factors such as alcohol intake and medications were not adjusted. Further analyses will be necessary to elucidate the effects of these factors.

From these findings, together with previous reports [3,6,21,22], we hereby propose a more efficient method of diagnosis of RHUC based on $\mathrm{FE}_{\mathrm{UA}}$ and SUA data (Figure 3), when physicians detect and examine hypouricemic individuals (SUA $\leq 3.0 \mathrm{mg} / \mathrm{dL}$ ) (Figure 3a). With hypouricemia, especially severe hypouricemia (SUA $\leq 1.0 \mathrm{mg} / \mathrm{dL}$ ) (Figure $3 \mathrm{~b}$ ), we propose the following three differential diagnoses (Figure $3 \mathrm{c}-\mathrm{j}$ ): (1) When the $\mathrm{FE}_{\mathrm{UA}}$ data of severe hypouricemia patients are high (typically $\mathrm{FE}_{\mathrm{UA}} ; 25-90 \%$ ) (Figure $3 \mathrm{c}$ ), these patients are predicted to be RHUC type 1 [6] (Figure 3h) because the laboratory data suggest that they should have two nonfunctional variants of URAT1 (Figure 3f). (2) When the $\mathrm{FE}_{\mathrm{UA}}$ data of severe hypouricemia patients are extremely high (typically $\mathrm{FE}_{\mathrm{UA}}>100 \%$ ) (Figure 3d), these patients are predicted to be RHUC type $2[21,22]$ (Figure 3i) because they are likely to have two nonfunctional variants of GLUT9 (Figure 3g). (3) When the FE data are not high and urinary uric acid (UA) levels are nearly zero in severe hypouricemia patients (Figure 3e), they are suspected of having xanthinuria [23] (Figure 3j). With mild 
hypouricemia $\left(2.0<\mathrm{SUA} \leq 3.0 \mathrm{mg} / \mathrm{dL}\right.$ ) (Figure $3 \mathrm{k}$ ), their $\mathrm{FE}_{\mathrm{UA}}$ data are usually normal or slightly high (typically $\mathrm{FE}_{\mathrm{UA}} ; 5-15 \%$ ) (Figure 31 ), and they are predicted to have one or zero nonfunctional variants of URAT1 or GLUT9 (Figure 3m). Detection of one nonfunctional variant of URAT1 (Figure 3n) or GLUT9 (Figure 3o) by genetic analyses is necessary to make a diagnosis of RHUC type 1 (Figure 3q) or type 2 [3] (Figure 3r). If nonfunctional variants of URAT1 or GLUT9 are not detected (Figure 3p), physicians should consider differential diagnosis of RHUC [1] (Figure 3s). Thus, even before genetic tests of URAT1 or GLUT9, FE $\mathrm{UA}_{\mathrm{UA}}$ and SUA data are very helpful for the practical diagnosis of RHUC.

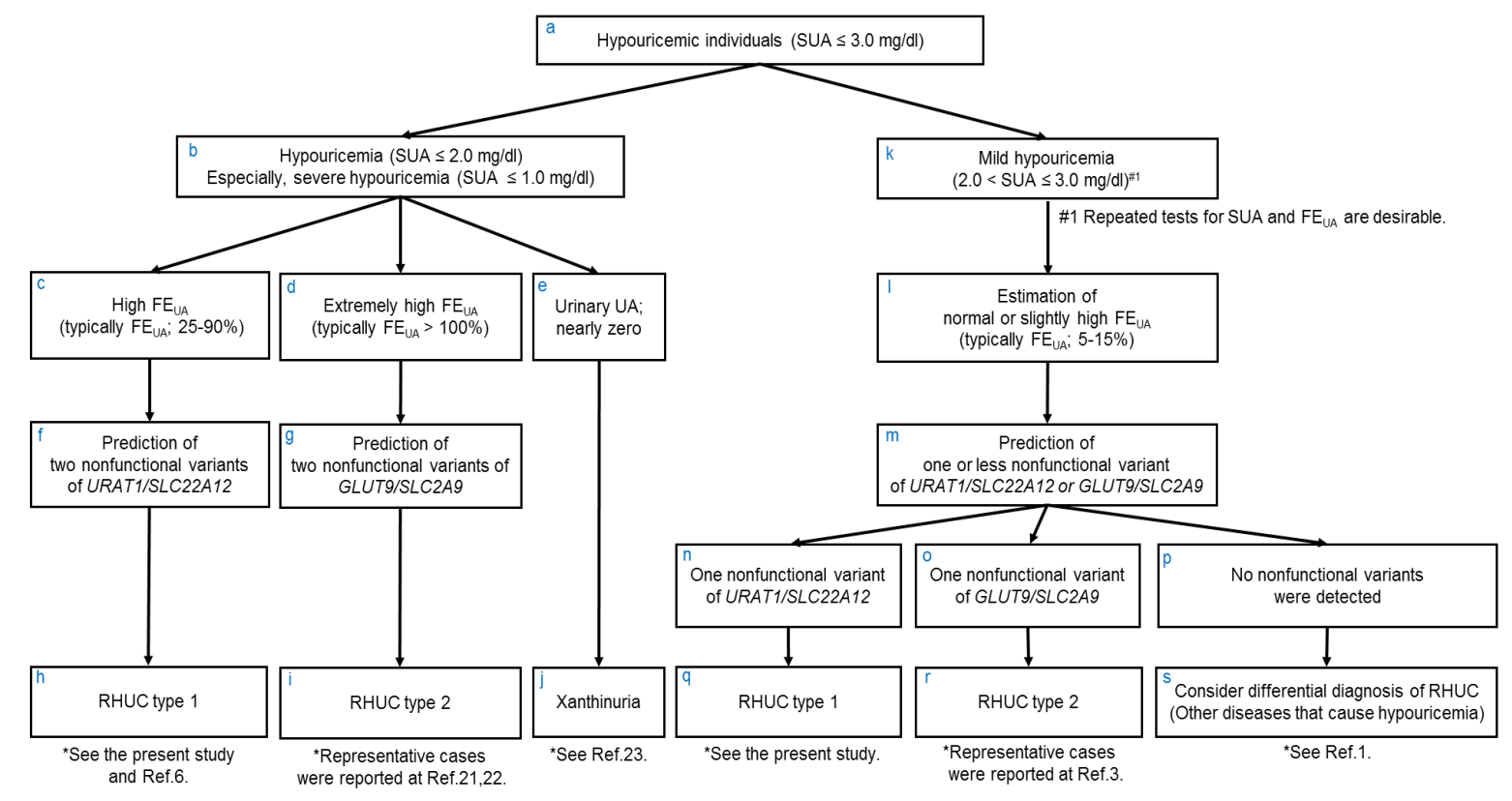

Figure 3. Flowchart to predict the number of nonfunctional variants of causative genes for RHUC based on FE $\mathrm{UA}_{\mathrm{UA}}$ and SUA data. Based on the findings of the present study, together with previous reports, we hereby propose a method of making a more practical diagnosis of RHUC even before genetic testing for URAT1/SLC22A12 or GLUT9/SLC2A9, when physicians detect and examine hypouricemic individuals (SUA $\leq 3.0 \mathrm{mg} / \mathrm{dL} ;(\mathbf{a})$ ). In those with hypouricemia (SUA $\leq 2.0 \mathrm{mg} / \mathrm{dL}$ ), especially with severe hypouricemia (SUA $\leq 1.0 \mathrm{mg} / \mathrm{dL})(\mathbf{b})$, their $\mathrm{FE}_{\mathrm{UA}}$ and urinary UA data should be investigated (c-e). These data will help to estimate RHUC type 1 or 2 due to two nonfunctional variants of URAT1 or GLUT9, or xanthinuria $(\mathbf{f}-\mathbf{j})$. Genetic analysis is needed to distinguish RHUC type 1 and type 2, but this flowchart shows that physicians should be able to predict the causative gene from patients' laboratory data before performing a genetic analysis. On the other hand, in those with mild hypouricemia $(2.0<\mathrm{SUA} \leq 3.0 \mathrm{mg} / \mathrm{dL} ;(\mathbf{k}))$, their FE $\mathrm{UA}_{\mathrm{U}}$ data are estimated to be normal or slightly high $(\mathbf{l})$, which makes it possible to predict there to be one or no nonfunctional variants of URAT1 or GLUT9 (m). With these mild hypouricemia patients, detection of one nonfunctional variant of URAT1 (n) or GLUT9 (o) by genetic analysis is needed to make a diagnosis of RHUC type 1 (q) or type 2 (r). Physicians should consider differential diagnosis of RHUC (s) if no nonfunctional variants of URAT1 or GLUT9 are detected (p). Additionally, see Figure 4 regarding the patterns of FE $\mathrm{UA}$ and

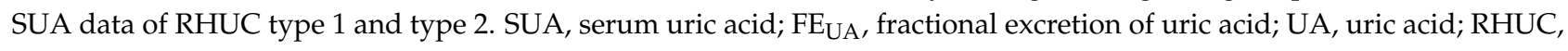
renal hypouricemia. 


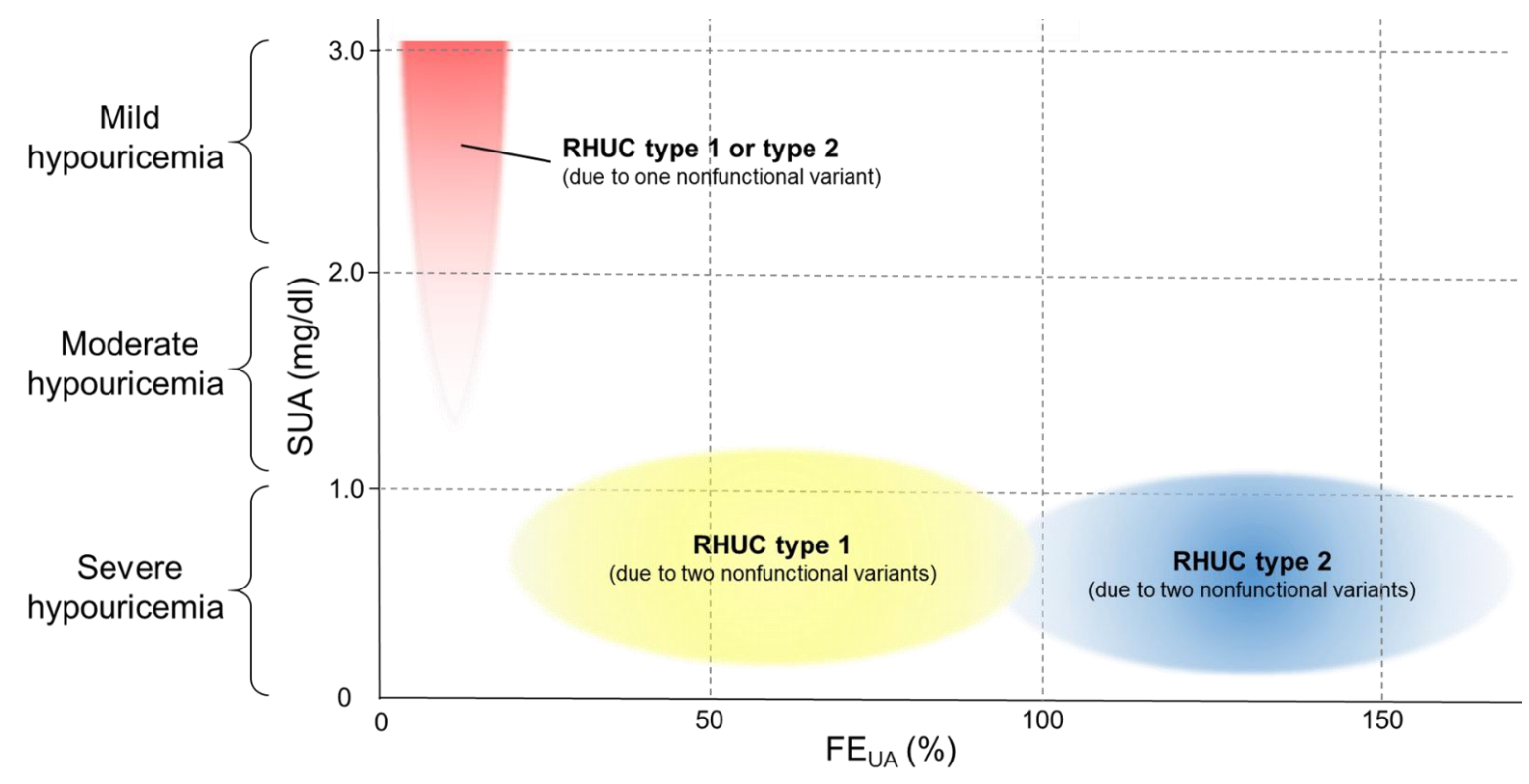

Figure 4. Specific distribution patterns of $\mathrm{FE}_{\mathrm{UA}}$ and SUA of RHUC type 1 and 2 with the number of nonfunctional variants. This figure shows the relationship between RHUC and the number of nonfunctional variants of URAT1 or GLUT9 based on the patterns of $\mathrm{FE}_{\mathrm{UA}}$ and SUA data. The horizontal and vertical axes respectively show $\mathrm{FE}_{\mathrm{UA}}$ and SUA. Hypouricemic individuals (SUA $\leq 3.0 \mathrm{mg} / \mathrm{dL}$ ) were divided into the following three groups: "severe hypouricemia" (SUA of $\leq 1.0 \mathrm{mg} / \mathrm{dL}$ ), "moderate hypouricemia" (SUA of 1.1-2.0 mg/dL) and "mild hypouricemia" (SUA of 2.1-3.0 mg/dL). Typical laboratory data (FE $\mathrm{FEA}_{\mathrm{UA}}$ and SUA) for RHUC type 1 or 2 patients are shown in the following three patterns: The yellow and blue areas show "RHUC type 1 due to two nonfunctional variants of URAT1" (see also Figure $3 \mathrm{~h}$ ) and "RHUC type 2 due to two nonfunctional variants of GLUT9" (see also Figure 3i), respectively. The red area shows "RHUC type 1 due to one nonfunctional variant of URAT1 (see also Figure 3q)" or "RHUC type 2 due to one nonfunctional variant of GLUT9 (see also Figure 3r)". Data from RHUC patients with other diseases, including renal dysfunction, might land in different areas from

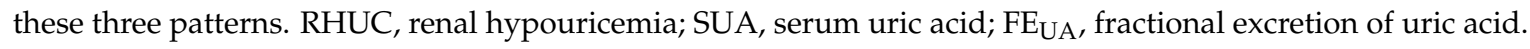

Furthermore, Figure 4 illustrates the three specific distribution patterns of FE $\mathrm{UA}_{\mathrm{A}}$ and SUA data for RHUC, based on the number of nonfunctional variants of URAT1 or GLUT9.

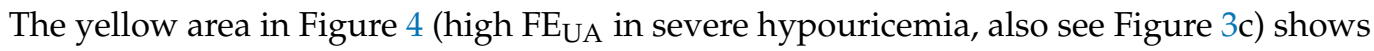
the pattern for "RHUC type 1 due to two nonfunctional variants of URAT1". The blue area in Figure 4 (extremely high $\mathrm{FE}_{\mathrm{UA}}$ in severe hypouricemia, also see Figure $3 \mathrm{~d}$ ) shows the pattern for "RHUC type 2 due to two nonfunctional variants of GLUT9". The red area in Figure 4 (normal or slightly high $\mathrm{FE}_{\mathrm{UA}}$ in mild hypouricemia, also see Figure 31) shows RHUC type 1 or RHUC type 2 due to one nonfunctional variant of URAT1 or GLUT9. Interestingly, as shown in Figure 4, "RHUC due to two nonfunctional variants of URAT1 or GLUT9" and "RHUC due to one nonfunctional variant of URAT1 or GLUT9" were found to exhibit specific distribution patterns of FE $\mathrm{UA}_{\mathrm{A}}$ and SUA data. This suggests that it should be possible, even before genetic tests for URAT1 or GLUT9, to predict the presence and number of nonfunctional variants of URAT1 or GLUT9 from the specific patterns shown in Figure 4. These three specific patterns of FE $F_{U A}$ and SUA data can also be useful for the selection of the appropriate genetic tests for URAT1 or GLUT9, for the efficient and rapid diagnosis of RHUC.

As shown in Figures 3 and 4, there is an obvious difference between $F_{\mathrm{UA}}$ levels of "RHUC type 1 due to two nonfunctional variants URAT1" and those of "RHUC type 2 due to two nonfunctional variants of GLUT9". We consider one of the reasons for this difference to be as follows. While GLUT9 could be only one renal urate reabsorption transporter at the basolateral membrane in the human kidney, URAT1 is likely to play a role in urate handling alongside organic anion transporter 10 (OAT10/SLC22A13), the third and recently reported renal urate reabsorption transporter [24], at the apical membrane. 
We believe that our findings will assist with a more practical diagnosis of RHUC based on the specific distribution patterns of $\mathrm{FE}_{\mathrm{UA}}$ and SUA data. A more accurate diagnosis of RHUC will not only enable clinicians to prevent complications of RHUC such as EIAKI and urolithiasis, but will also lead us to a better understanding of the mechanism of urate handling and hypouricemia.

\section{Conclusions}

In summary, we have demonstrated four important findings. First, we investigated the prevalence of hypouricemia (SUA $\leq 2.0 \mathrm{mg} / \mathrm{dL}$ ) and mild hypouricemia individuals $(2.0<$ SUA $\leq 3.0 \mathrm{mg} / \mathrm{dL})$ among 30,685 Japanese participants, and discovered the prevalence of hypouricemic individuals (SUA $\leq 3.0 \mathrm{mg} / \mathrm{dL}$ ) to be $0.97 \%$ in males and $6.94 \%$ in females. Second, we revealed a very high frequency of NFV-URAT1 (W258X and R90H) in 1040 hypouricemia and mild hypouricemia individuals (SUA $\leq 3.0 \mathrm{mg} / \mathrm{dL}$ ). Third, the presence and number of NFV-URAT1 alleles assists with estimating the FE $\mathrm{UA}_{\mathrm{UA}}$ data of hypouricemic individuals (SUA $\leq 3.0 \mathrm{mg} / \mathrm{dL}$ ). This suggests that the FE $\mathrm{UA}_{\mathrm{A}}$ data of hypouricemic individuals should be very useful for predicting the presence and number of NFV-URAT1 alleles, and also assists with diagnosis of RHUC type 1. Fourth, we were able to propose how to make a more reliable diagnosis of RHUC based on the distribution patterns of $\mathrm{FE}_{\mathrm{UA}}$ and SUA data.

These findings have the potential to lead to a more practical diagnosis of RHUC based on specific patterns of laboratory data, and therefore a revision of the next edition of the clinical practice guideline for RHUC.

Author Contributions: Conceptualization, Y.K., A.N. and H.M.; formal analysis, Y.K., A.N. and H.M.; investigation, Y.K., A.N., S.S. (Seiko Shimizu), Y.T., M.K., S.S. (Satoko Suzuki), S.I., H.N. and H.M.; resources, Y.N., A.H., S.K.-K., K.S., T.T. (Takashi Tamura), R.I., H.U., M.H., K.T. (Kenji Takeuchi), K.A., T.T. (Toshiro Takezaki), K.T. (Keitaro Tanaka) and K.W.; data curation, Y.K., A.N., S.S. (Seiko Shimizu) and H.M.; writing—original draft preparation, Y.K., A.N., Y.T. and H.M.; writing-review and editing, Y.K., A.N., Y.T. and H.M.; visualization, Y.K., A.N. and H.M.; supervision, T.T. (Tappei Takada), M.T., K.I., N.S. and H.M.; project administration, H.M.; funding acquisition, A.N., Y.T., H.N., K.T. (Kenji Takeuchi), K.A., T.T. (Toshiro Takezaki), K.T. (Keitaro Tanaka), K.W. and H.M. All authors have read and agreed to the published version of the manuscript.

Funding: This study was supported by grants from the Ministry of Education, Culture, Sports, Science and Technology (MEXT) of Japan, including JSPS KAKENHI Grants (Nos. 20H00566, 20K23152, 20K10522, 21H03350, 17H04128, 25293145, 221 S0002 and 16H06279), the Ministry of Defense, the Kawano Masanori Memorial Foundation for the Promotion of Pediatrics and the Gout Research Foundation of Japan. The J-MICC Study was supported by Grants-in-Aid for Scientific Research from MEXT, including those for Priority Areas (No. 17015018) and Innovative Areas (No. 221S0001), as well as by a JSPS KAKENHI grant (No. 16H06277 [CoBiA]).

Institutional Review Board Statement: The study was conducted according to the guidelines of the Declaration of Helsinki, and approved by the institutional ethical committees (National Defense Medical College and Nagoya University).

Informed Consent Statement: Informed consent was obtained from all subjects involved in the study.

Data Availability Statement: The data presented in this study are available upon request from the corresponding author.

Acknowledgments: We are grateful for all the participants involved in this study. We are also indebted to K. Morichika, M. Miyazawa, M. Seki, S. Fujiwara, Y. Mori, R. Tanaka and M. Horie for genetic analysis, and N. Hamajima and H. Tanaka, for sample collection and their continuous encouragement of our study.

Conflicts of Interest: The authors declare no conflict of interest. 


\section{References}

1. Nakayama, A.; Matsuo, H.; Ohtahara, A.; Ogino, K.; Hakoda, M.; Hamada, T.; Hosoyamada, M.; Yamaguchi, S.; Hisatome, I.; Ichida, K.; et al. Clinical practice guideline for renal hypouricemia (1st edition). Hum. Cell 2019, 32, 83-87. [CrossRef]

2. Enomoto, A.; Kimura, H.; Chairoungdua, A.; Shigeta, Y.; Jutabha, P.; Cha, S.H.; Hosoyamada, M.; Takeda, M.; Sekine, T.; Igarashi, T.; et al. Molecular identification of a renal urate anion exchanger that regulates blood urate levels. Nature 2002, 417, 447-452. [CrossRef]

3. Matsuo, H.; Chiba, T.; Nagamori, S.; Nakayama, A.; Domoto, H.; Phetdee, K.; Wiriyasermkul, P.; Kikuchi, Y.; Oda, T.; Nishiyama, J.; et al. Mutations in glucose transporter 9 gene SLC2A9 cause renal hypouricemia. Am. J. Hum. Genet. 2008, 83, 744-751. [CrossRef]

4. Ishikawa, I. Acute renal failure with severe loin pain and patchy renal ischemia after anaerobic exercise in patients with or without renal hypouricemia. Nephron 2002, 91, 559-570. [CrossRef]

5. Kikuchi, Y.; Koga, H.; Yasutomo, Y.; Kawabata, Y.; Shimizu, E.; Naruse, M.; Kiyama, S.; Nonoguchi, H.; Tomita, K.; Sasatomi, Y.; et al. Patients with renal hypouricemia with exercise-induced acute renal failure and chronic renal dysfunction. Clin. Nephrol. 2000, 53, 467-472. [PubMed]

6. Ichida, K.; Hosoyamada, M.; Hisatome, I.; Enomoto, A.; Hikita, M.; Endou, H.; Hosoya, T. Clinical and molecular analysis of patients with renal hypouricemia in Japan-influence of URAT1 gene on urinary urate excretion. J. Am. Soc. Nephrol. 2004, 15, 164-173. [CrossRef]

7. Sakiyama, M.; Matsuo, H.; Shimizu, S.; Nakashima, H.; Nakamura, T.; Nakayama, A.; Higashino, T.; Naito, M.; Suma, S.; Hishida, A.; et al. The effects of URAT1/SLC22A12 nonfunctional variants, R90H and W258X, on serum uric acid levels and gout/hyperuricemia progression. Sci. Rep. 2016, 6, 20148. [CrossRef] [PubMed]

8. Wakasugi, M.; Kazama, J.J.; Narita, I.; Konta, T.; Fujimoto, S.; Iseki, K.; Moriyama, T.; Yamagata, K.; Tsuruya, K.; Asahi, K.; et al. Association between hypouricemia and reduced kidney function: A cross-sectional population-based study in Japan. Am. J. Nephrol. 2015, 41, 138-146. [CrossRef] [PubMed]

9. Kuwabara, M.; Niwa, K.; Ohtahara, A.; Hamada, T.; Miyazaki, S.; Mizuta, E.; Ogino, K.; Hisatome, I. Prevalence and complications of hypouricemia in a general population: A large-scale cross-sectional study in Japan. PLoS ONE 2017, 12, e0176055. [CrossRef]

10. Kawasoe, S.; Ide, K.; Usui, T.; Kubozono, T.; Yoshifuku, S.; Miyahara, H.; Maenohara, S.; Ohishi, M.; Kawakami, K. Distribution and Characteristics of Hypouricemia within the Japanese General Population: A Cross-Sectional Study. Medicina $2019,55,61$. [CrossRef]

11. Asai, Y.; Naito, M.; Suzuki, M.; Tomoda, A.; Kuwabara, M.; Fukada, Y.; Okamoto, A.; Oishi, S.; Ikeda, K.; Nakamura, T.; et al. Baseline data of Shizuoka area in the Japan Multi-Institutional Collaborative Cohort Study (J-MICC Study). Nagoya J. Med. Sci. 2009, 71, 137-144.

12. Hamajima, N.; Group, J.-M.S. The Japan Multi-Institutional Collaborative Cohort Study (J-MICC Study) to detect geneenvironment interactions for cancer. Asian Pac. J. Cancer Prev. 2007, 8, 317-323.

13. Ichida, K.; Matsuo, H.; Takada, T.; Nakayama, A.; Murakami, K.; Shimizu, T.; Yamanashi, Y.; Kasuga, H.; Nakashima, H.; Nakamura, T.; et al. Decreased extra-renal urate excretion is a common cause of hyperuricemia. Nat. Commun. 2012, 3, 764. [CrossRef]

14. Gabrikova, D.; Bernasovska, J.; Sokolova, J.; Stiburkova, B. High frequency of SLC22A12 variants causing renal hypouricemia 1 in the Czech and Slovak Roma population; simple and rapid detection method by allele-specific polymerase chain reaction. Urolithiasis 2015, 43, 441-445. [CrossRef]

15. Stiburkova, B.; Gabrikova, D.; Cepek, P.; Simek, P.; Kristian, P.; Cordoba-Lanus, E.; Claverie-Martin, F. Prevalence of URAT1 allelic variants in the Roma population. Nucleosides Nucleotides Nucleic Acids 2016, 35, 529-535. [CrossRef] [PubMed]

16. Nakayama, A.; Matsuo, H.; Abhishek, A.; Ichida, K.; Shinomiya, N. Guideline Development Committee of Clinical Practice Guideline for Renal Hypouricemia., First clinical practice guideline for renal hypouricemia: A rare disorder that aided the development of urate-lowering drugs for gout. Rheumatology 2021, keab322. [CrossRef] [PubMed]

17. Ichida, K.; Hosoyamada, M.; Kamatani, N.; Kamitsuji, S.; Hisatome, I.; Shibasaki, T.; Hosoya, T. Age and origin of the G774A mutation in SLC22A12 causing renal hypouricemia in Japanese. Clin. Genet. 2008, 74, 243-251. [CrossRef] [PubMed]

18. Wakida, N.; Tuyen, D.G.; Adachi, M.; Miyoshi, T.; Nonoguchi, H.; Oka, T.; Ueda, O.; Tazawa, M.; Kurihara, S.; Yoneta, Y.; et al. Mutations in human urate transporter 1 gene in presecretory reabsorption defect type of familial renal hypouricemia. J. Clin. Endocrinol. Metab. 2005, 90, 2169-2174. [CrossRef]

19. Toyoda, Y.; Kawamura, Y.; Nakayama, A.; Nakaoka, H.; Higashino, T.; Shimizu, S.; Ooyama, H.; Morimoto, K.; Uchida, N.; Shigesawa, R.; et al. Substantial anti-gout effect conferred by common and rare dysfunctional variants of URAT1/SLC22A12. Rheumatology 2021, keab327. [CrossRef]

20. Kawamura, Y.; Toyoda, Y.; Ohnishi, T.; Hisatomi, R.; Higashino, T.; Nakayama, A.; Shimizu, S.; Yanagi, M.; Kamimaki, I.; Fujimaru, R.; et al. Identification of a dysfunctional splicing mutation in the SLC22A12/URAT1 gene causing renal hypouricaemia type 1: A report on two families. Rheumatology 2020, 59, 3988-3990. [CrossRef]

21. Dinour, D.; Gray, N.K.; Campbell, S.; Shu, X.; Sawyer, L.; Richardson, W.; Rechavi, G.; Amariglio, N.; Ganon, L.; Sela, B.A.; et al. Homozygous SLC2A9 mutations cause severe renal hypouricemia. J. Am. Soc. Nephrol. 2010, 21, 64-72. [CrossRef] [PubMed]

22. Dinour, D.; Gray, N.K.; Ganon, L.; Knox, A.J.; Shalev, H.; Sela, B.A.; Campbell, S.; Sawyer, L.; Shu, X.; Valsamidou, E.; et al. Two novel homozygous SLC2A9 mutations cause renal hypouricemia type 2. Nephrol. Dial. Transplant. 2012, 27, 1035-1041. [CrossRef] 
23. Ichida, K.; Amaya, Y.; Okamoto, K.; Nishino, T. Mutations associated with functional disorder of xanthine oxidoreductase and hereditary xanthinuria in humans. Int. J. Mol. Sci. 2012, 13, 15475-15495. [CrossRef] [PubMed]

24. Higashino, T.; Morimoto, K.; Nakaoka, H.; Toyoda, Y.; Kawamura, Y.; Shimizu, S.; Nakamura, T.; Hosomichi, K.; Nakayama, A.; Ooyama, K.; et al. Dysfunctional missense variant of OAT10/SLC22A13 decreases gout risk and serum uric acid levels. Ann. Rheum. Dis. 2020, 79, 164-166. [CrossRef] [PubMed] 